\title{
Counselling Needs of Orphaned Children: A case Study of Harare Metropolitan Children
}

\author{
Jenny Shumba \\ jennymshumba@gmail.com \\ George Moyo \\ Faculty of Education, University of Fort Hare, 50 Church Street, East London South Africa
}

\section{Doi:10.5901/mjss.2014.v5n11p145}

\begin{abstract}
In recent years Zimbabwe has experienced a high death rate due to HIVIAIDS and other causes. This has resulted in massive numbers of children of school - going age, becoming orphans due to loss of one or both parents. This study sought to investigate the experiences of the orphans with regard to counselling support the children received in schools. The study adopted an interpretivist paradigm. A case study design was used. Data were gathered from 13 purposively selected secondary school students and 4 school counsellors using phenomenological in-depth interviews and life narratives. The study established that although orphans suffer multiple consequences after bereavement, they do not get adequate counselling due to; lack of clear school bereavement policies; negative attitudes towards counselling by teachers; lack of proper planning and the reactive nature of bereavement counselling in the schools. The study recommends that school authorities must ensure that counsellors are supported and empowered to deliver effective counselling services to orphans. It also recommends that further research which seeks to go beyond the dominant Euro-centric bereavement counseling models; and which can lay the basis for the development of Afro-centric approaches to bereavement counselling must be undertaken.
\end{abstract}

Keywords: parentally bereaved children, orphans, bereavement experiences, school bereavement counselling

\section{Introduction}

Zimbabwe has a population of approximately 13 million people (CSO, 2009) and a death rate of 13.58 deaths /1000 population. Currently, Zimbabwe is experiencing deaths due to Human immunodeficiency virus infection (HIV) and Acquired immunodeficiency syndrome (AIDS), other communicable diseases and accidents (UNAIDS 2008; UNICEF 2003). As a result, many children have been orphaned. Youthnet (2008) states that by 2007, one in every five (1:5) children worldwide had lost a parent or both parents as a result of HIV and AIDS. This amounted to an estimated 15 million orphaned children under the age of 18 (UNAIDS, 2008). Of these, 11.6 million live in Zimbabwe and other SubSaharan countries. By 2007, Zimbabwe had an orphan population resulting from communicable diseases of 1 million (UNAIDS 2008; Zimbabwe CSO, ORC Marco and the Boston Globe, 2008).

Efforts have been made by the government of Zimbabwe to address the plight of Orphans and other Vulnerable Children (OVC). Having ratified the United Nations Convention on the Rights of the Child (ACRWC), the government of Zimbabwe crafted the Zimbabwe National Orphan Care Policy (ZNOCP), the National Plan of Action 1 and National Plan of Action II as an attempt to try and cushion OVCs from social ills such as, poverty, abuse, exploitation and violence (The National Action Plan for Orphans and Vulnerable Children Phase II 2011). Most of these children are in schools and seem to bear the brunt of the realities of their orphanhood. Apart from these social burdens, the bereaved children carry heavy psychological baggage as explained below which render them eligible for counselling. However, this service seems to be ad hoc and patchy (Rembe, 2006; Ribbens McCarthy, 2007) in schools where they spend the bulk of their time.

\section{Consequences of Bereavement}

Parentally bereaved children endure social, physical and psychological consequences (Saito, Monash, Keogh, Dhlembeu, Bergua, \& Mafico, 2007). Bereavement makes them vulnerable and renders them a population at risk (Skinner, Tsheko, Mtero-Munyati, Segwabe \& Mfecane, 2006). Over and above bereavement, additional risk factors include severe chronic illness of a parent or caregiver, poverty, hunger, lack of access to services, inadequate clothing or 
shelter, overcrowding, deficient caretakers, disability, physical or sexual violence. All children are vulnerable and deemed at risk by virtue of their being children (UNICEF, 2004). This has implications on how bereaved children should be handled, especially after the death of their parents as they would be vulnerable and in need of protection, love and care.

\subsection{Psychological consequences}

Bereavement may be understood as posing particular difficulties in relation to the 'normal' development of adolescence (Harrison \& Harrington 2001; Ribbens McCarthy \& Jessop, 2005). According to Cluver \& Gardner (2006), there is little research available but increasing concern regarding the psychological well-being of orphans in Africa. Bereaved children experienced multiple stressors that complicated their grief process. Literature reveals that children experience anger, guilt, yearning, denial, shock, disbelief, depression (Ribbens McCarthy 2006), low cognition (Gwandure, 2007); anxiety, irritability (Makaya, Mboussou, Bansimba, Ndinga, Ambendet \& Puruehnce, 2002); lowered self- esteem and motivation (Rembe, 2006); sadness, pain, fear (Foster, Makufa, Drew, Mashumba \& Kambeu, 1997); suicidal ideation, aggression and posttraumatic stress disorder (de Witt \& Lessing 2005; Ndetei et al, 2008; Yule 2001). Parental death is viewed as very depressive. However, psychological consequences of bereavement resulting from the death of a parent differ in the levels of depression depending on the nature of death. Kelly (2009) posits that a higher incidence of depression occurs when parental loss is accidental or due to suicide. Following the death of their parents, bereaved children suffer from psychosomatic disorders, such as, sleep disorders, fatigue, eating disorders, headaches, stomachaches, crying and nightmares. The psychological experiences given above might have negative impact on children's lives; schooling included, and thus need to be investigated to find how best bereaved children can be assisted through trying times.

\subsection{Social consequences}

Bereaved children also suffer social consequences. These may be understood as creating particular vulnerabilities in the context of the relatively powerless and institutionalised phase of life, termed "youth" (Harrison \& Harrington 2001; Ribbens McCarthy \& Jessop 2005). Parental death often dismantles a bereaved child's social life. For instance, studies in Zimbabwe and other African countries revealed the following: the introduction of child headed family establishments; relocation to join other families (Tahir et al, 2005; Rembe, 2006); emergence of behaviour problems such as pilfering and truancy (Black, 1981); vulnerability to child physical and sexual abuse due to lack of parental protection and guidance; loss of social security and protection from stigmatisation; poverty (Central Statistical Office (CSO) [Zimbabwe] and Macro International Incorporation, 2007; Van Dyk, 2008, Bray, 2003), have earlier sexual debut than non-orphans (Tahir et al, 2005) and are easy catch for terrorist recruitment (Scott Evertz in Salaam, 2005). A study in South Africa by Davids et al (2006) revealed that children become vulnerable and at risk when compromised in terms of material things. Some turn to deviance such as running away from home and drug abuse (de Witt \& Lessing, 2005). In support, Rembe (2006) indicated that bereaved children often compared life before and after the parent's death; preferring the former. The above mentioned social consequences of bereavement create a ripple effect. For example, the death of a parent means loss of a breadwinner, poverty ensues and loss of school fees, thus, deepening the plight of the bereaved child. There is greater need for social support during bereavement (Jewitt, 2001). Schools need to be aware of these social consequences that affect bereaved children when dealing with them.

\section{Interventions and Postventions to Support Bereaved Children}

Given the complexity of the situation the bereaved students are thrown into following the death of their parents, different interventions exist for them. According to Stortz (2007), the programmes include socio-economic and psychological support. Counselling is one form of psychological support that is rendered to bereaved children.

\subsection{The notion of school bereavement counselling}

Counselling is a structured conversation between a counsellor and one or more clients that assists the client to work through particular problems he or she faces (SAT, 2001). It can be defined as a process that involves an interpersonal relationship between someone actively seeking help and someone willing to assist. Counselling, thus, gives people the opportunity to be heard, gives them time to talk, cry, shout or think (Dent, 2004). The main goal of counselling is maximising resilience and reducing risks and to change a situation that is risky and 'disruptive to the extent that one cannot continue through the normal passage of life ....without stress, dissatisfaction or unhappiness' (Connect Module 1 , 
2004:5). Hence, school bereavement counselling is one of the posttension strategies that can be employed to alleviate the plight of bereaved secondary school children.

School counsellors must be aware of and bolster grieving children's positive development as this helps them to cope with grief (Eppler, 2008). Counsellors would, thus, need to be conversant with approaches to counselling bereaved children in their contexts. However, as Muthukrishna and Sam in Mpofu (2011) reveal, counsellors' training is based on Western Models and thus they internalise and practise counselling with a Eurocentric bias that negates the African context. If this is so, then there is a gap created by this type of counselling practice. Therefore, there is the need for counselling models and theories specific to the diverse and fluid African context. However, there is no homogeneity in the African context (Holdstick, 2000 in Mpofu, 2011). This implies taking cognisance of individual contexts of bereaved children's cases.

\subsection{Methodology}

\subsubsection{Design}

This was a multiple case study of 13 purposively selected secondary school children and 4 school counsellors from two secondary schools. The multiple cases were selected as they were considered information rich sites (Johnson \& Christensen, 2012; Mertens 2010) and it "helps ensure that the key research themes are addressed and that diversity ... is explored" (Carcary 2009). Bereaved children were selected for the express reason that they were bearers of privileged information as they had experienced death of their parents and the counsellors were in constant contact with these grieving secondary school children.

\subsubsection{Data Collection}

Phenomenological in-depth interviewing was conducted with bereaved students and counsellors in order to capture the students' bereavement experiences (Ribbens-McCarthy 2006). Life narratives were also used to collect data on the intimate experiences of the children that they may otherwise not have provided in the interview. These methods sought to give voice to the children and counselors.

\subsubsection{Data Analysis}

Interpretive phenomenological analysis was employed to analyse interview transcripts and life narratives. Textural and structural descriptions were given to allow themes to emerge from the data (Moustakas, 1994). Textural descriptions give "what was experienced" and structural descriptions relate to "how it was experienced." The focus was on explicating recurrent themes. For this study, the main themes were psychological experiences, physical experiences, sociological experiences, philosophical experiences and educational experiences. Results are presented below under these themes.

\subsubsection{Issues of rigour in qualitative research}

To ensure quality in this research the researchers used mechanically recorded data and presented verbatim accounts of the respondents as this guaranteed credible data. Phenomenological bracketing was also employed so as to capture unadulterated data from the respondents.

\subsubsection{Ethical issues}

Permission to conduct the study was sought from the Ministry of Education, Sport, Arts and Culture Head Office, Harare Provincial Office, District Education Office and School heads. Participants were assured of their anonymity and confidentiality as pseudonyms and codes were going to be used for the schools and respondents. Assurances were also given to the bereaved children that the life narratives would be used only for research purposes. Tape recording was done with the participants' signed consent that emphasised voluntary participation. The researchers were cautious in dealing with these children as bereavement is a sensitive issue and made concerted effort not to harm them more emotionally and at the same time had the trained school counsellors at hand. 


\section{Results}

Various themes emerged from the data gathered from bereaved children and school counsellors. The data are presented below.

\subsection{Pain}

Data revealed that students experienced pain and distress due to the death of their parents. For example, PPL4LM had this to say after her father's death, "...it was painful...because he was the only person I could talk to. What pained me is that I did not bid him farewell".

Due to this distress some children harboured feelings of revenge for their relatives. PPL2LM intimated that, "there is this thing that appears to be pushing me to want to bother my mother's relatives to help us revenge and claim our property". The hurt seemed to be very deep rooted and evoked deeper vengeful emotions for him to want to solicit help from the sympathetic maternal relatives.

Suicidal ideation was also evidenced due to the pain of loss. PPL6LM for instance, suggested this when she confided that:

The death of my mother really pained me. Up to now I am still in pain. If I go deep in thought about it...mmm...it stresses me and sometimes I think of committing bad things...sometimes wished I were dead. (PPL6LM)

\subsection{Nostalgia}

A deep sense of nostalgia and yearning for the deceased parent was also evident in PPL4M's words when she states: "...I now meet a lot of challenges and wish my father was around...I feel if, my father was alive I would not be in this kind of trouble.."For this child and others challenges were abound post death of their parents and they wish hands of time could be turned back.

\subsection{Child abuse}

The bereaved children's sentiments on challenges they encountered were also confirmed by the school counsellors in the following statements:

A pupil was being sexually abused by a guardian who happened to be the only close relative to the pupil. The aunt whose husband was the abuser/perpetrator defended her husband. The pupil is HIV positive and on medication. The matter was referred to Justice for Children but no immediate solution was found C1LM.

A girl orphan staying with an aunt, was made to wake up around 3 in the morning to do all the housework before going to school, also do the nappies for aunt's granddaughter, comes to school without eating, goes back home to find people have already eaten and that nothing had been left for her, prepares supper but cannot dish out food for herself, aunt then later dishes out a small portion for her. Babamukuru (aunt's husband) claims she is wife number two therefore could sleep with her...

Child labour-child made to do all housework/chores before coming to school, yet even when, guardian has got her/his children, they will be doing nothing or not much. Sexual-uncles proposing to sleep with the child C2M.

One would actually quiz; Who guards the guards? According to these counsellors the people who are supposed to be protecting the children turned to be protectors-cum-perpetrators. It would appear that bereaved children had a lot of intra-relational challenges to contend with after the death of their parents. The school needs to be well equipped to deal with these children.

\subsection{Inter-relationships}

Data also revealed varied inter- relationship challenges. Children's voices below attest to this:

...I ran away from home because of my stepmother.... she said she wanted to stay with us but as you know it is hard to look after someone else's child. I ran away to maiguru's (aunt)... (PPL2LM)

I was very distressed by my sister. When we went home, I stayed with one sister and the other one took my younger sister in ...but...mmm. my sisters chased us away and we ended up staying at our parents' home- just the two of us... we then decided to go to our brother in Harare. I had joined the ZCC church so when the members from Harare came to 
our place with their bus we grabbed the opportunity and asked for a lift to Harare. That is how we ended up here (PPL6LM).

PPL2LM and PPL6LM were forced to flee their homes due to relationship conflicts. This could exacerbate the bereaved children's vulnerability as the protective and safe cover of the family institution disappears.

For PPL7LM the bereavement due to his mother's death presents him with new challenges. He says:

Now I have a problem with my sister who is in form 2. She is emotional and always crying for our mother. My father drinks a lot. He is an alcoholic. When he gets his money on pay day, he gives most of the money to me. When he wants money for beer and anything he asks from me. I have to budget for food, my sister's books and her other needs, toiletries, my bus fare and everything needed in the home... (PPL7LM)

Role redefinition emerges for PPL7LM. He becomes the head of household and takes over the running of the home despite having one parent still alive. His father is incapacitated by alcohol consumption. He lamented having to do his "mother's roles."

PPL1LM also has the following story to tell:

I have to do business before I come to school.... I have to since we need to eat and dad trained me about the business. Uncle does not know much, he came from the rural areas/village...you see. I bought a cellphone for him too (PPL1LM). PPL1LM qualifies to be called a child breadwinner as he is the sole provider for the family members' upkeep through the selling of haulage trucks spare parts. Despite the fact that he is in form 3 and is fifteen, he is taking care of his twenty four year old uncle and his wife.

\subsection{Issues of inheritance}

Issues of inheritance, especially property grabbing, were rife in the bereaved children's experiences. PPL2LM and PPL7LM had this to say:

The sharing of my father's property did not please me. His brothers grabbed the property leaving us with nothing claiming that we ran away from home. (PPL2LM)

Because my mother did not write a will, there were problems with inheritance. My mother had a house left for her by her parents when they died. Mum owned the house ... She had step-brothers and sisters who were clamouring for the house left to my mum and brother. There was a will then-my grandparents had written a will. (PPL7LM, Data set 2)

It would appear that apart from grieving for their late parents, the orphaned children had to grieve too for their lost inheritance. It also appears that the type of relationship the child had with the other people in his or her social milieu determined how the child experienced bereavement. This is revealed in the family relations portrayed in the data. The spatial context in which the child existed also had a role to play in what the child experienced after the death of a parent or parents, for example, relocating. This context made each child's case to be unique as each case bore different social and emotional effects. In essence, context and the bereavement experience are inextricably interwoven in relation to one's lived experience.

\subsection{Educational experiences}

Although some students professed no change in their performance after the death of their parents, some indicated that their performance was negatively affected (PPL6M; PPL3LM), with lack of concentration being the militating factor. For example one child said:

My father's death definitely affected me. I failed at school... I only passed 2 subjects. I am now a bit better at school. After the death I was away for only 3 days, however when I was at school I lacked concentration due to worry. ....Now......am concentrating. (PPL6M)

Bereavement also resulted in children being transferred from one school to another. PPL2LM gave this account:

I was transferred from Speciss College back to my present school because my aunt could not afford the high fees. When my mother died I was transferred to Speciss College where I joined a group of friends and started drinking beer. We would buy beer and drink it before going home and when I got home would just sleep. PPL2LM 
Due to the loss of their parents through death, some students dropped out of school, whilst others contemplated dropping out of school due to the challenges related to bereavement, such as lack of school fees and lack of parental guidance.

The students posited:

...I even thought of dropping out of school because my father is a drunkard...Playing the role of a mother when you are a student is such a hard thing. Now I am about to write my final exams, so how can I overcome this problem? ... My education is really being affected by this situation. (PPL7LM's Life narrative)

The death of my mother affected my studies. I could not concentrate in my studies. I even contemplated dropping out of school because my father is a drunkard and before my mother died she was the one who used to provide school fees. I was also afraid of my aunts and uncles because they wanted to snatch mother's house from us... this affects me because sometimes I get to school late trying to look for bus fare. (PPL7LM)

The death of my father affected my school work. I now have problems with school fees. We are five and four of us need school fees as a result we are always sent home to collect school fees. Sometimes money comes from our aunt (my mother's younger sister) in the United Kingdom.

I used to be very good in class but now deteriorating because I am always absent. I used to be at a boarding school where we had ample time to study - we really would study but now we have to look after mama. My sister and I take turns to look after our mother.

When father was there, he would urge us to study - he would say "you should read and read," therefore, I was very good. (PPL4M)

For PPL5LM her woes were different. She narrated that:

Yes the death of my mother affected me. When I tried to read a book at home, I would see her face in the book and then I would stop looking at the book and stop reading. I have never been absent at my current school but when I was at my mother's rural home I was always absent so that I could help my grandmother because she is old and is a weakling.PPL5LM

Apart from being a caregiver for her ailing grandmother and perpetual absenteeism from school, she would see apparitions of her dead mother in her book and she would abandon reading. It meant rescinding from her core business as a learner.

\subsection{Counselling experiences at school}

The revelations by different respondents may be an indication that there is no clear cut policy in the two schools visited on the reporting of bereavements. Some children indicated that their classmates or friends reported their bereavement to teachers. Another one said the deputy head got wind of her bereavement because they live in the same neighbourhood. The captions below, however, indicate a sad state of affairs where bereaved children were only identified when the researchers got to the school for data collection.

I did not tell the teachers. Ma'am (senior woman) asked about us when you had come. (PPL2M)

The teachers did not know until the senior woman came to ask for children who lost their parents. (PPL5M)

The school only got to know about the deaths last week when the deputy head announced that she wanted to talk to children who had lost their parents in the last year. (PPL2LM)

...At this current school, other students and teachers did not know about my mother's death. I got no help. They only got to know about it when the deputy head came to our classroom last week to identify the students who had lost parents. (PPL3LM)

It remains unclear as to how bereaved children should be identified at school.

When asked about the counselling services they were offered at school, the bereaved children gave the following responses:

...Hmm ... teachers did nothing. There has been no counselling so far. (PPL1M)

The deputy head stays in the same area but heard after the funeral, no support. I never got any counselling. (PPL3M)

I did not get any help from the school. My friends only conveyed their condolences. (PPL5M)

The teachers said things will be ok after a while. I have had no counselling by a school counsellor. (PPL6M)

I did not get counselling at school. (PPL2LM) 
I never got any assistance at my previous school... (PPL3LM)

Counsellors also had reservations on counselling provision as shown below:

\begin{abstract}
Lack of support from colleagues. One actually arguing that giving too much support emotionally and otherwise would worsen the plight of these orphans and that they would have to stand up and face their own struggles. (C2LM)

Sometimes, otherwise, I am usually generally at a loss because these children would like to receive every day attention, day to day affection. Of course, the words of comfort release their stress.(C2LM)

I feel I can counsel the girls but sometimes it is very difficult when girls have been raped by breadwinners because everybody in the family turns against them. There are several pupils whose parents or guardians say that they were raped and were in a worse predicament than themselves (pupils).

The process of reporting is rather slow because some of the cases ought to go through psychological services. (C2LM)
\end{abstract}

The data reflect that there is lack of synchronisation in the delivery of services. Counsellors need peer support in counselling bereaved children. This might have a bearing on the counselling that is rendered or not rendered to orphans in the schools.

\title{
4.8 Bereavement support
}

Data registered some positive aspects. For example, PPL4LM said:

I am always happy at school. I interact with my friends. I got a lot of support from my schoolmates... From the time I felt teachers and my friends were on my side, I got my strength back and started working hard again. (PPL4LM)

It can be deduced that with support bereaved children can traverse through bereavement with some degree of confidence.

\subsection{Philosophical experiences}

It emerged that bereavement is instrumental in the creation of new orientations and paradigms towards life as many of the bereaved students highlighted their new perspectives to life post death of their parents which were as a result of reflection of the evolution of their lives.

I am now focusing on the future (PPL1LM)

I have accepted my predicament and say that is life. I want to become a pilot so that I help my mother and sister (PPL6M).

It has taught me that life changes. It is up to me now to work hard in school and pass and have a bright future. (PPL2LM).

I realise my father is gone...I have to live with it and I have to work hard so that I achieve what my father wished for me. (PPL4LM).

(With her head balancing on her left hand) This experience has taught me to be serious with my school work so that I can take care of my younger siblings (pause) and to look after mama. I need to look after her; for instance, my mother was in hospital and was discharged last Friday. She bought some medicines but could not afford the other drugs not found in the hospital. My aunt in the UK is not working at the moment so the husband is the one actually helping us (PPL4M).

It taught me that life is not a joke and something to waste. Before, I did not take life seriously. Now I just want to be into my work. The pastor said he would come to talk to us but is still to see us (PPL3M).

The statements above signified change in the mental mapping of the lives of the children and this evidenced reflectivity on the part of the bereaved students. Bereavement, thus, makes one reflective as these bereaved children had reflected upon their experiences of bereavement and came up with future oriented resolutions. The change also signifies the concept of temporality (self and time) as the bereaved learner's trajectory shifts from one point to the other, marked by the past, present and future. The children had to accept their predicament (being bereaved and the experiences thereof) in order for them to be future oriented.

Data also revealed that for some children, God's divine intervention was needed to salvage them from the doldrums of unpalatable lives.

This experience has taught me that it is not only me who has lost parents. There are some very young children. If I 


\begin{abstract}
continuously think about my bereavement ... How about younger children? What I aim for is to do any job God grants me. (PPL5LM)

It means that we all have our time to live and our time to die. I have to just live my life. Just to continue to live my life. (PPL1M)

I now look up to God's grace so that I have a good life so that I can look after my mother's children. (PPL6LM)
\end{abstract}

This is a clear indication that children are in dire need of someone to lean on and school counsellors should capitalise on this and render required assistance.

\title{
5. Discussion
}

The study established that although there are some universal bereavement experiences, there are some that are unique to individuals. For instance, loss and grief are universal and cut across culture, age and gender (Di Ciacco 2008:26; Meade 2007; Rosenblatt in Stroebe et al 2008). However, Stroebe et al in Shumba (2011:200) point out that this assertion is "based on the positivist perspective and is in opposition to the post modern view that looking at universals is rather retrogressive and gives a misinformed view about the nature of knowledge...." Phenomenological studies, on the other hand, seek to capture unique details about each case. It is these 'unique details' on children's bereavement experiences that this study sought to unravel.

Counselling bereaved children should not be viewed from a universalist point of view only as bereaved children's experiences differ. In this vein, a particularist view should also be adopted as it accommodates variance (Shumba 2011). Grief or bereavement experiences vary with culture, age, gender and religion (Klass in Encyclopedia of Death and Dying 2011). For example, rituals cited by the bereaved students in the study varied and included Christian and ancestral worship. This is in agreement with Rothaupt \& Becker's (2007:12) contention that "Rituals vary greatly from culture to culture and provide a window into how a group cares for those who mourn."

The study also revealed that there were family feuds due to wrangles on inheritance. Inheritance feuds are not peculiar to this study only, but are common in African extended family setups (Rose 2008). However, what is worrisome is that the bereaved children bear the brunt as they find themselves embroiled in feuds. Furthermore, property grabbing benefits other surviving relatives at the bereaved children's expense. Children in this study, for instance had property being confiscated by uncles and aunts, rendering them destitute and "disinherited" (Justice for Children Trust/Legal Resources Foundation Consultation Workshop 2008:np). This negatively affected them psychologically, socially and in their schooling (Abebe \& Aese, 2007; Cluver, Operario, Lane, \& Kganakg (in press) in Young Carers Policy Briefs, 2011; Cluver, Orkin, Boyes, Gardner \& Meinck (in press) in Young Carers Policy Briefs, 2011). These situations invite close collaboration between the school and other stakeholders such as the family, Ministry Social Welfare Ministry of Education, Sport, Arts and Culture and Ministry of Justice and Legal and Parliamentary affairs.

This study established that children experienced primary and secondary or derivative losses due to the death of their parents. Holland (2001), Wolchik et al. (2008) and Gertler et al. (2004) contend that the initial loss leads to other losses. Scott (2007) calls these compound losses. The initial and primary loss, in this case, being the death of a parent or both parents and the secondary losses were, for example, the loss of a parent led the child to incur other losses such as, loss of emotional security; loss of financial security, loss of source of subsistence, loss of carer, loss of a home, loss of a confidante, loss of advisor, loss of fathomed birthright (inheritance), loss of guidance, loss of meaning, loss of childhood, loss of family structure. Prompt intervention is needed for children experiencing situations portrayed here to avert pathological reactions by bereaved children.

The death of a significant other enables one to re-examine his or her existence and attempt to draw meaning from the bereavement experience (Newman \& Newman, 2006; Stroebe et al., 2001). In line with this, findings in this research were that children rediscovered themselves after the bereavement and all children interviewed proffered, in their own way, that they found some new meaning to life from the bereavement of their parents. New ways of thinking and new work ethics were reflected by the children as the death seemed to mark some beginning of new insights into life. The researchers, Litchenthal et al. (2010), also posit that the new perspective to life the child gets after the bereavement of the parent could be enhanced when the child is guided and has support that helps in the formulation and management of the new philosophy. To sum this up, Frankl (1963) in Hogan and Schmidt (2002:617) posits that people can make sense of suffering and find meaning and purpose despite the horrendous loss. Their argument is in line with the Personal Growth Construct that is premised on the belief that "growth can emerge following difficult life events" (Hogan \& Schmidt, 2002:617). Parental death is one such difficult life event that against all odds might bring about personal positive growth to certain individuals. Counselling support should thus be rendered to bereaved children to assist them to remain positive. 
However, findings reflected that bereavement counselling support in the schools visited lacked proper planning and was reactive in nature. This is in agreement to Jenkins \& Polat (2006) in Fox \& Butler (2009); Rembe (2006) and Ribbens- McCarthy (2006). Data also revealed lack of clear school bereavement policies in the selected schools, such as, identification and reporting ones. However, this is in direct contrast to what happens in countries such as the United Kingdom, where bereavement reporting policies have been put in place in schools (Holland, 2001; Ribbens-McCarthy, 2006). In the study it was also found that some teachers had negative attitudes towards counselling and some lacked confidence in dealing with bereaved children. Holland (2001) attests to this when he suggests that although the issue of childhood bereavement was rated to be very high in Hull and Humberside schools in the United Kingdom, some counsellors lacked skills to support bereaved children. Shumba (2011:214) argues;

This signalled a training gap in these schools and this scenario also signals the same gap in the training of counsellors in the current study as some counsellors indicated fear of counselling boys or students with sensitive issues.

What appears peculiar is that the phobia reflected by the counsellors can imply that bereaved children may be left to find their own means of dealing with their bereavement. Counsellors need to be well equipped with skills to boost their confidence in dealing with delicate issues they encounter. Lack of collegial support was cited in the responses by one counsellor. The need for support from colleagues was emphasised by Tatar (2009) as it makes the counsellor's job lighter.

\section{Conclusion}

Based on the above findings, the study concludes that bereaved children experienced a variety of circumstances that impacted both positively and negatively on their schooling and rendered them in need of bereavement counselling. It also concludes that bereaved students in selected Harare schools were not receiving adequate bereavement counselling due to; lack of clear school bereavement policies; negative attitudes towards counselling by teachers; lack of proper planning and the reactive nature of bereavement counselling in the schools; schools neither had policies nor laid down procedures on bereavement counselling.

\section{Recommendations}

The study recommends that:

- The study recommends capacity building and development of counsellors to empower to deliver effective counselling services to orphans.

- The study also recommends that further research which seeks to go beyond the dominant Euro-centric bereavement counseling models; and which can lay the basis for the development of Afro-centric approaches to bereavement counselling must be undertaken.

\section{References}

Abebe, T. \& Aese, A. (2007). Children, AIDS and the Politics of Orphan Care in Ethiopia: The extended family revisited. Social Science and Medicine. 64 (10):2058-2069.

Carcary, M. (2009). The Research Audit Trail- Enhancing Trustworthiness in Qualitativelnquiry. The Electronic Journal of Business Research Methods. 7(1):11-24.

Black, D. (1981). What happens to bereaved children? Therapeutic

Education, 2, 15-20.

Bray, R. (2003). Predicting the Social Consequences of Orphanhood in South Africa.

Centre for Social Science Research, Social Science Unit. University of Cape Town CSSR Working Paper.

Central Statistical Office (CSO) [Zimbabwe] and Macro International Inc (2007). Zimbabwe Demographic and Health Survey 2005-2006. Calverton, Maryland: CSO and Macro International Inc.

Cluver, L. \& Gardner, F. (2007). Risk and Protective Factors for Psychological well-being of Children Orphaned by AIDS in Cape Town: A Qualitative Study of Children and Caregivers' Perspectives. AIDS Care. 19 (3):318-25.

Cluver, L., Operarario, D., Lane, T., \& Kganakg, M. (In press) Educational Shortfalls among "Young Carers" in the South African AIDS Epidemic. Journal of Adolescent Research in Young Carers Policy Briefs, July 2011.

Cluver, L., Orkin, M., Boyes, M., Gardner, F. \& Meink, F. (in press). "Transactional Sex

amongst AIDS orphaned \& AIDS Affected Adolescents Predicted by Abuse and Extreme Poverty. Journal of AIDS in Young Carers Policy Briefs July 2011.

Connect Module I, (2004). Certificate in Systemic Family Counselling (Child). Harare:

CONNECT. 
Davids, A., Letlape, L., Magome, K., Makgoba, S., Mandivenyi, C., Mdwaba, T., Ntjantja, N., Nkomo, N., Mfecane, S. \& Skinner, D. (2006). A Situation Analysis of Orphans and Vulnerable Children in four Districts of South Africa. Cape Town: HSRC Press.

Dent, A. (2004). Bereavement Counselling.

http:/www.bbc.co.uk/health/emotional_health/bereavement/bereavement_counselling.shtml. Accessed 28 August 2004.

De Witt, W. \& Lessing, A.C. (2005). Educator's Views on the Needs \& Support of HIVIAIDS Orphans in their Psychosocial Development. Journal of Child and Mental Health. 17(1):13-22.

Di Ciacco, J.A. (2008). The Colours of Grief: Understanding a child's Journey through

Loss from Birth to Adulthood. London: Jessica Kingsley Publishers.

Eppler, C. (2008a). Exploring Themes of Resiliency in Children after the Death of a Parent. Freeonlinelibrary.com. Accessed 12 June 2010.

Eppler, C. (2008b). Professional School Counselling. Available http://findarticles.com/p/articles/mi_mOKOC/ Accessed 12 June 2010.

Foster, G., Makufa, C., Drew, R., Mashumba, S. \& Kambeu, S. (1997). Perception of Children and Community Members Concerning the Circumstances of Orphans in Rural Zimbabwe. AIDS Care. 10:391-405.

Fox, C.L. \& Butler, I. (2009) Evaluating the effectiveness of a school-based counselling service in the UK. British Journal of Guidance and Counselling. 37(2): 95-106.

Gertler, P., Levine, D.I. \& Ames, M. (2004) Schooling and Parental Death. The Review of Economics and Statistics.86(1):211-225 http://www.jstor.org/stable/3211668 Accessed 26 May 2010

Gwandure, C. (2007). Home -based Care for Parents with AIDS: Impact on Children's Psychological Functioning. Journal of Child and Adolescent Mental Health 19 (1) 29-44.

Harisson, L. \& Harrington, R. (2001). Adolescents' Bereavement Experiences, Prevalence, Association with Depressive Symptoms and use of Services. Journal of Adolescence 24 (2):159-169.

Hogan, B. M. \& Schmidt, L. A. (2002). Testing the Grief to Personal Model using Structural Equation Modeling. Death Studies. 26:615634.

Holland, J. (2001). Understanding Children's experiences of Parental Bereavement. London: Jessica Kingsley Publishers.

Jewitt , L. (2001). AIDS, Bereavement and Support: Building Resilience and Hope for the Future. Children FIRST, 4 (39).

Johnson, B. \& Christensen, L. (2012). Educational Research: Quantitative, Qualitative and Mixed Approaches. Thousand Oaks: SAGE Publications.

Justice for Children Trust/Legal Resources Foundation Consultation Workshop (2008)

Inheritance in the Face of HIV in Zimbabwe. Harare: SAFAIDS.

Kelly, J. (2009). Parental Death has Major Impact on Depression Risk in Youth: American Journal of Psychiatry. 786-794. Available Url: accessed 12-02-2010 www.medscape .com/viewarticle/706384.

Lichtenthal, W.G., Currier, J.M., Neimeyer, R. A. \& Keesee, N.J. (2010). Sense and Significance: a mixed methods examination of meaning after the loss of one's child. Journal of Clinical Psychology 2010. 66(7):791-812. www.ncbi.nhm.nih.gov. Pubmed. Accessed 03-02-2011.

Makaya, J., Mboussou, F., Bansimba, T., Ndinga, H., Latifou, S., \& Ambendet Puruehnce, M. (2002). Assessment of Psychological Repurcussions of AIDS next to 354 AIDS Orphans in Brazzaville, 2001: Barcelona.

Meade, K. D. (2007). Transcending Culture: Universality of Grief. Unpublished Master of Social Work Dissertation. Smith College for Social Work. Northampton. Massachusetts.

Mertens, D. M. (2005). Research and Evaluation in Education and Psychology: Intergrating Diversity with Quantitative, Qualitative, and Mixed Methods. (2nd Edition). Thousand Oaks: Sage Publications.

Mertens, D.M. (2010). Research and Evaluation in Education and Psychology: Integrating Diversity with Quantitative, Qualitative and Mixed Methods. $3^{\text {rd }}$ edition. Thousand Oaks: Sage Publications.

Moustakas, C. (1994). Introduction to Phenomenology. London: Routledge.

Mpofu, E. (2011). Counselling People of African Ancestry. Cambridge: Cambridge University Press.

Ndetei, D.M., Khasakhala, L.I.., Seedat, S., Syanda, J., Ongecha-Owuor, F.A., Kokonya, D.A. \& Mutiso, V.N. (2008). Psychometric Properties of the Multidimensional Anxiety Scale for Children (MASC) amongst Nairobi Public Secondary school Children. Journal of Child \& Adolescent Mental Health. 20 (2):101-109.

Newman, B.M. \& Newman, P.R. (2006). Development through Life: A Psychosocial Approach. Thomson Learning: London.

Rembe, S. (2006). Report on Country Preparedness in Dealing With HIVIAIDS in Education and Training Sector among SADC Member States: A Case Study Of Zimbabwe.

Ribbens McCarthy, J. R. (2006). Young People's Experiences of Loss and Bereavement: Towards an Interdisciplinary Approach. New York: Open University Press.

Ribbens McCarthy, J.R. \& Jessop, J. (2005). The Impact of Bereavement and Loss on Young People. Online. Available url:http:/www.jrf.org.uk/publications/impact-bereavement-loss-young people. Accessed 12 July 2009.

Rose, L.L. (2008). Children's property and Inheritance Rights and their Livelihoods: The Context of HIV and AIDS in Southern and East Africa. LSP Working Paper 39. Food and Agriculture Organization of the United Nations.

Rothaupt, J. W. \& Becker, K. (2007) A Literature Review of Western Bereavement Theory: From Decathecting to Continuing Bonds. The family Journal. 2007; 15:6-15.

Saito, S., Monash, R., Keogh, E., Dhlembeu, N., Bergua, J. \& Mafico, M. (2007). Baseline for the Evaluation of a NAP for Orphans and Other Vulnerable Children Using UNAIDS Core Indicators: A Case Sttudy in Zimbabwe. Vulnerable Children and Youth Studies. 
Vol 2 Issue 3, December 2007:198-210. UNICEF.

SAT (2001). Counselling Guidelines on Palliative Care and Bereavement. Harare: SAT.

Scott, C. E. (2007). Childhood Bereavement: A Qualitative Study. A Dissertation Submitted in Partial to the Faculty of School of Professional Psychology , Pacific University, forest Grove. Oregon in partial fulfilment of the requirements for the Degree of Doctor of Psychology.

Skinner, D., Tsheko, N., Mtero-Munyati, S., Segwabe, M., Chibatamoto, P. \& Mfecane,

S. (2006). Towards a Definition of Orphaned and Vulnerable Children. AIDS and Behaviour. 10: 619- 626.

Shumba, (2011). Secondary School Children's Experiences of Bereavement: Implications for School Counselling in Harare Metropolitan Province Unpublished Thesis. University of Fort Hare.

Stortz, L. (2007). An Integrated Literature Review of the Impact of Parental HIV/AIDS

Deaths on African Children and Families. Unpublished Undergratuate Honors Dissertation. University of North Carolina. Chapel Hill.

Stroebe, M., Hansson, R.O., Stroebe, W. \& Schut, H. (Eds.). (2001). Handbook of Bereavement Research: Consequences, Coping and Care. Washington, D.C.: American Psychological Association.

Stroebe, M.S.., Hansson, R.O., Stroebe, W. \& Schut, H. (Eds.). (2008). Handbook of Bereavement Research and Practice: Advances in Theory and Intervention. Washington, D.C.: American Psychological Association.

Tahir, S., Finger, W. \& Ruland, C. (2005). Adolescents: Orphaned \& Vulnerable in the Time of HIVIAIDS. Youthlens on Reproductive Health and HIVIAIDS No 18

Tatar, M. (2009). Teachers Turning for Help to School Counsellors and Colleagues: Toward a Mapping of Relevant Predictors. British Journal of Guidance and Counselling. www.informaworld.taylor\&francis.com smpp/title content $=6713406946$. Accessed 3 March 2011.

The Encyclopedia of Death and Dying (2011). Death Education. http://www.deathreference.com/Da-Em/Death-Education. html. Accessed 21 July 2011.

UNAIDS (2008). Report on the global AIDS epidemic. UNAIDS.

UNICEF (2003). Zimbabwe Human Development Report 2003: Redirecting our responses to HIV and AIDS: towards reducing vulnerability- the ultimate war for survival. Poverty Reduction Forum 2003. Harare: UNICEF.

UNICEF (2004). Children in Residential Care: The Zimbabwean Experience. UNICEF.

Van Dyk, A. (2008). HIV/AIDS Care and Counselling: A Multidisciplinary Approach. Cape Town. Maskew Miller Longman.

Wolchik, S.A., Ma, Y., Tein, J., Sandler, I.N. \& Ayers, T.S. (2008) Parentally Bereaved

Children's Grief: Self-System Beliefs as Mediators of the Relations Between grief and Stressors and Caregiver-child Relation Quality. Death Studies. 32. 597-620.

Youthnet (2008). http:www.youthnet.fhl.org

Yule, W. (2001) Post-traumatic stress disorder in children and adolescents. International Review of Psychiatry 2001, 13:194-200.

Zimbabwe Central Statistical Office in Collaboration with Maryland based ORC MARCO, The Boston Globe (2008). Daily HIVIAIDS Report. Available url: www.kaisernetwork.org/daily-reports/rep-index.cfm?DR.10. 
